\title{
INOCULAÇÃO DE Fusarium oxysporum f. sp. phaseoli EM SEMENTES DE FEIJOEIRO ATRAVÉS DE RESTRIÇÃO HÍDRICA ${ }^{1}$
}

\author{
MARIA LUIZA NUNES COSTA ${ }^{2}$ \\ JOSÉ DA CRUZ MACHADO ${ }^{3}$ \\ RENATO MENDES GUIMARÃES ${ }^{4}$ \\ EDSON AMPÉLIO POZZA \\ DÊNIS ORIDE ${ }^{5}$
}

\begin{abstract}
RESUMO - Em diversos estudos sobre a associação de Fusarium oxysporum f. sp. phaseoli com sementes de feijoeiro, há necessidade de obtenção de sementes infectadas, inclusive com graus de incidência diferenciados. Assim, objetivou-se com este trabalho testar a metodologia de inoculação de Fusarium oxysporum f. sp. phaseoli em sementes de feijoeiro utilizando meio batata-sacarose-ágar (BSA) adicionado com solutos que proporcionam restrição hídrica ao meio, permitindo o crescimento do fungo e inibindo a germinação das sementes. Foram utilizados os solutos sacarose, cloreto de potássio e manitol, adicionados ao meio BSA para obter os potenciais osmóticos de $-0,8,-1,0,-1,2$ $\mathrm{MPa}$, e diferentes tempos de exposição das sementes ao
\end{abstract}

fungo (36, 72, 108 e 144 h). Para avaliar os efeitos da colonização fúngica nas sementes, utilizaram-se testes de germinação e sanidade (blotter-test). O crescimento micelial do fungo foi avaliado in vitro, não havendo inibição em nenhum dos potenciais hídricos e solutos utilizados, observando-se maior crescimento nos potenciais osmóticos de 0,8 e -1,0 MPa. Nos maiores períodos de tempo, 108 e 144 $\mathrm{h}$, o crescimento micelial foi maior, afetando o desempenho das sementes. Dos solutos utilizados, o $\mathrm{KCl}$ proporcionou a maior incidência média $(64 \%)$ de sementes com Fusarium oxysporum f. sp. phaseoli. Quando as sementes permaneceram por $144 \mathrm{~h}$ sobre o mesmo soluto, a incidência foi de $70 \%$.

TERMOS PARA INDEXAÇÃO: Colonização, fungo, solutos, sacarose, cloreto de potássio, manitol, potencial osmótico.

\section{INOCULATION OF BEAN SEEDS WITH Fusarium oxysporum f. sp. phaseoli THROUGH WATER RESTRICTION TECHNIQUE}

\begin{abstract}
The objective of the present work was to test methodology of inoculation of bean seeds with Fusarium oxysporum f. sp. phaseoli using water restriction technique. For that, three solutes, sucrose, potassium chloride and manitol, added to the medium potato-sucrose-agar, PSA at three water potentials $(-0.8,-1.0,-1.2 \mathrm{MPa})$ and four duration periods of the exposition of seeds to the fungus (36, 72, 108 and 144h) were used. The effects of the fungus on the performance of the seeds and emerged plants were evaluated looking at germination and
\end{abstract}

health (blotter-test). The mycelial growth of the fungus in vitro, was not reduced by any osmotic treatment. Higher growth of the fungus was observed at osmotic potentials of -0.8 e $-1.0 \mathrm{MPa}$. At longer durations of exposition of the seeds to the pathogen, 108 e 144h, mycelial growth of the fungus was higher and affected seed performance. The greatest mean incidence of Fusarium oxysporum $\mathrm{f}$. sp. phaseoli $(64 \%)$ was detected on seeds in wich $\mathrm{KCl}$ was used. At $144 \mathrm{~h}$ of inoculation period on that solute, the incidence was of $70 \%$.

INDEX TERMS: Colonization, fungi, sucrose, potassium chloride, mannitol, osmotic potential.

\footnotetext{
1. Parte da tese apresentada a Universidade Federal de Lavras/UFLA - Caixa Postal 37 - 37200-000 - Lavras, MG, pelo primeiro autor, para obtenção do grau de mestre em Agronomia na área de Fitopatologia.

2. Engenheiro Agrônomo, Estudante de Pós-Graduação em Agronomia/Fitopatologia - UFV.

3. Professores do Departamento de Fitopatologia da UFLA.

4. Professor do Setor de Sementes da UFLA.

5. Engenheiro Agrônomo, bolsista de aperfeiçoamento.
} 


\section{INTRODUÇÃO}

O feijoeiro comum (Phaseolus vulgaris L.) é um dos principais alimentos da dieta da população brasileira, sendo uma importante fonte de proteina e apresentando uma boa adaptação em diferentes condições climáticas.

A ocorrência de determinados patógenos nas sementes, mesmo em taxas relativamente baixas, pode gerar grandes perdas na produção, como é o caso de Fusarium oxysporum f.sp. phaseoli, agente etiológico da murcha ou amarelecimento de Fusarium em feijoeiro. A incidência desse fungo nas sementes de feijoeiro produzidas em algumas regiões do País vem aumentando nos últimos anos (LEAL e BOLKAN, 1981; NUNES JÚNIOR e MENTEN, 1985; MENEZES et al., 1981; SANTOS et al., 1996), em razão do uso, por parte dos produtores, de grãos em substituição às sementes (PEREIRA e YOKOYAMA, 1999). Nesses casos, além da baixa germinação e vigor, as sementes possuem baixa qualidade sanitária.

Fusarium oxysporum f. sp. phaseoli (Fop) é um microrganismo que sobrevive no solo, sendo transmitido por sementes, sobrevivendo em seu interior, em impurezas associadas às sementes e em restos de cultura (KENDRICK e SNYDER, 1942; MACHADO, 1999). Dessa forma, o controle da referida doença torna-se extremamente difícil e, muitas vezes, impossibilitado. Do ponto de vista epidemiológico, a associação desse fungo com sementes é um fato relevante, sendo responsável pela introdução e disseminação de inóculo inicial entre regiões de cultivo.

Muitos fungos transmitidos por sementes iniciam suas atividades por ocasião da semeadura, os quais podem resultar em diminuição do estande e/ou tombamento de pré ou pós-emergência (AGARWAL e SINCLAIR, 1987; MENTEN, 1991).

A diagnose preventiva no estádio de sementes, assim como o tratamento das mesmas visando ao controle do inóculo infectivo são medidas que podem, portanto, auxiliar em grande escala o combate a esse tipo de doença.

Para auxiliar os estudos de Fop associados às sementes, há necessidade, porém, de disponibilização das mesmas com o inóculo, inclusive em graus de incidência diferenciados. Em estudo de detecção do patógeno na semente, de avaliação de fungicida no controle da transmissão do patógeno pelas sementes, de ensaio de melhoramento visando à resistência ou tolerância ao patógeno (AGARWAL e
SINCLAIR, 1987) e de comportamento epidemiológico de doenças transmitidas por sementes, poderse-á utilizar essa metodologia para obtenção das sementes infestadas.

A metodologia de inoculação de fungos em sementes sobre meio de cultura batata-dextroseágar (BDA), utilizando a técnica de restrição hídrica, foi empregada por Carvalho (1999), para a obtenção de sementes de feijoeiro com Colletotrichum lindemuthianum. A técnica de restrição hídrica foi avaliada em testes de sanidade (blotter test) visando a substituir o uso de 2,4-D e em meio sólido, para inibir a germinação das sementes de feijão, arroz (COUTINHO, 2000) e algodão (MACHADO, 2002) sendo observada a inibição da germinação das sementes, sem efeito estimulante ou inibitório, no desenvolvimento do fungo, quando comparado às metodologias padronizadas.

A avaliação da influência da restrição hídrica no crescimento fúngico tem sido realizada utilizando meio sólido controlado osmoticamente (COOK e DUNIWAY, 1981; WEARING e BURGESS, 1979; CHANDLER et al., 1994; ALAM et al., 1996; ADEBAYO e HARRIS, 1971; BROWNELL e SCHNEIDER, 1985). O crescimento micelial de Fusarium é, em geral, intensificado em meios de cultura com menores potenciais osmóticos, havendo crescimento normal até -3,0 $\mathrm{MPa}$ (MANANDHAR e BRUEHL, 1973).

Conduziu-se este trabalho com o objetivo de obter sementes de feijoeiro infectadas por Fop usando a técnica de restrição hídrica como metodologia de inoculação, pois na inoculação por meio de restrição hídrica, as sementes podem ser infectadas, já que permanecem por período maior de tempo em contato com o fungo, em comparação com a técnica de inoculação por meio de embebição das sementes em suspensão de conídios.

\section{MATERIAL E MÉTODOS}

Foram realizadas inoculações de sementes de feijoeiro, com Fop utilizando como substrato batatasacarose-ágar (BSA) modificado (com restrição hídrica) com três solutos (sacarose, cloreto de potássio e manitol), que proporcionam restrição hídrica em meio sólido.

Nos testes de crescimento micelial, utilizou-se o delineamento experimental inteiramente casualizado, com 4 repetições em esquema fatorial $3 \times 3$, combinando soluto (sacarose, cloreto de potássio e manitol) com potencial osmótico $(-0,8,-1,0,-1,2$

Ciênc. agrotec., Lavras. V.27, n.5, p.1023-1030, set./out., 2003 
$\mathrm{MPa}$ ), sendo testemunha o crescimento em meio BSA. E nos testes de germinação e sanidade, utilizou-se o delineamento experimental em blocos casualizados com esquema fatorial $3 \times 3 \times 4+4$, no qual combinaram-se soluto (sacarose, $\mathrm{KCl}$ e manitol), potencial (-0,8, -1,0 e -1,2 MPa), tempo (36, 72, 108 e 144 horas) de incubação e tratamento adicional (sementes inoculadas nos tempos 36, 72, 108 e $144 \mathrm{~h}$ em meio BSA).

\section{Obtenção de isolados de Fop e das sementes de feijoeiro}

Os isolados de Fop utilizados no trabalho foram obtidos de sementes de feijoeiro, sendo as culturas puras do patógeno mantidas em meio Synthetic Nutrient Agar (SNA), (NIREMBERG, 1981). Os isolados foram mantidos a $10^{\circ} \mathrm{C}$ em tubos contendo mistura de solo-areia-composto orgânico, previamente esterilizados, sendo utilizado para inoculação o isolado que se mostrou mais patogênico ao feijoeiro no teste de patogenicidade, realizado de acordo com Rava et al. (1996).

Foram utilizadas sementes de feijoeiro (cv. Carioca), safra 1999, sendo sua qualidade fisiológica avaliada de acordo com as Regras de Análise de Sementes (BRASIL, 1992). A qualidade sanitária das sementes foi verificada por blotter-test (MACHADO, 1988).

\section{Inoculação das sementes com Fusarium oxys- porum f. sp. phaseoli}

O inóculo do patógeno foi cultivado em meio de aveia para obtenção de uma suspensão de conídios. Essa suspensão foi calibrada para a concentração de $10^{6}$ conídios/ml e $1 \mathrm{ml}$ foi espalhado em placas de Petri de $15 \mathrm{~cm}$ de diâmetro, contendo $40 \mathrm{ml}$ de meio BSA modificado. As placas foram acondicionadas em incubadora, regulada à temperatura de $25^{\circ} \mathrm{C}$ e fotoperíodo de 12 horas. Após o crescimento micelial do fungo por cinco dias, foram colocadas aproximadamente 125 sementes, previamente esterilizadas com hipoclorito de sódio $1 \%$ por 1 minuto, em cada placa, e novamente incubadas nas mesmas condições. As sementes permaneceram sobre a colônia fúngica por 4 períodos de tempo $(36,72,108$ e 144 h) para cada soluto e concentração.

O meio com restrição hídrica foi preparado pela adição dos solutos sacarose, cloreto de potássio e manitol ao BSA, e para cada soluto, foram utilizadas três concentrações diferentes, de modo a propor- cionar potenciais osmóticos de -0,8,-1,0 e -1,2 MPa. $\mathrm{O}$ cálculo das concentrações dos solutos foi realizado pelo software SPPM (MICHEL e RADCLIFFE, 1995).

Após o término dos períodos de incubação das sementes a Fop, essas foram retiradas das placas e distribuídas sobre papel de filtro, em temperatura ambiente, para retornarem ao teor de umidade inicial. Após três dias, as sementes foram colocadas em sacos de papel e armazenadas em câmara fria, onde permaneceram até o momento das avaliações.

\section{Avaliação da metodologia de restrição hídrica em meio agarizado para inoculação de semen- tes de feijoeiro com Fop}

A eficiência da metodologia de inoculação do Fop em sementes de feijoeiro, utilizando meio de cultura BSA contendo os solutos para obter diferentes potenciais osmóticos, foi avaliada considerando-se os parâmetros: a) crescimento micelial; b) teste de sanidade e c) porcentagem de germinação.

$\mathrm{O}$ crescimento micelial foi realizado utilizando o meio BSA modificado em placas de Petri de 10 $\mathrm{cm}$ de diâmetro. Ao centro, colocou-se um disco de 5 $\mathrm{mm}$ de diâmetro, do fungo cultivado por 7 dias, à temperatura de $20^{\circ} \mathrm{C}$ e fotoperíodo de $12 \mathrm{~h}$. Em seguida, as placas foram acondicionadas em incubadora regulada a $25^{\circ} \mathrm{C}$, com fotoperíodo de 12 horas, durante 8 dias. $\mathrm{O}$ crescimento micelial foi medido diariamente pelo diâmetro médio das colônias e o cálculo do índice de crescimento micelial (ICM) do fungo foi realizado de acordo com Oliveira (1991) nas diferentes combinações de solutos, concentrações e tempo de incubação.

A sanidade foi avaliada utilizando o blotter-test, sendo as sementes incubadas em placas de Petri de 15 $\mathrm{cm}$ de diâmetro, contendo três folhas de papel de filtro esterilizadas e umedecidas com água destilada esterilizada. Adicionou-se o sal de ácido 2,4diclorofenoxiacético, concentração de 10 ppm, à água destilada para evitar a germinação das sementes no período de incubação. As placas foram mantidas em câmara de crescimento sob luz negra (radiação na faixa de 320-400 nm), com fotoperíodo de $12 \mathrm{~h}$, à temperatura de $20^{\circ} \mathrm{C} \pm 2^{\circ} \mathrm{C}$, num período de 7 dias.

A observação das sementes para identificação da micoflora foi realizada com o auxílio do microscópio estereoscópico, e quando necessário, utilizou-se o microscópio ótico para confirmação das estruturas do fungo. 
O teste de germinação em rolo de papel foi conduzido com 4 repetições de 50 sementes em papel germitest (papel-toalha) umedecido com água destilada esterilizada, 2,5 vezes o peso do papel seco, em germinador regulado à temperatura constante de $25^{\circ} \mathrm{C} \pm 2^{\circ}$. As avaliações foram realizadas seguindo os critérios estabelecidos pelas Regras para Análise de Sementes.

As análises estatísticas dos experimentos foram realizadas utilizando os programas SISVAR e SAS. O contraste de médias para comparar as médias dos tratamentos com a testemunha dos parâmetros avaliados foi o teste de t. As médias entre os tratamentos foram comparadas pelo teste ScottKnott ou regressão, de acordo com a natureza dos dados, quantitativos ou qualitativos. Nas equações de regressão realizadas, foram calculados os pontos de máximo das curvas.

\section{RESULTADOS E DISCUSSÃO}

O crescimento micelial de Fop não foi afetado pelos diferentes solutos, mas sim pelos diferentes potenciais de restrição hídrica de cada soluto. A adição de sacarose, cloreto de potássio e/ou manitol até o potencial osmótico - $0.92 \mathrm{MPa}$ provocou estímulo do crescimento do fungo em relação à testemunha, mas a partir desse potencial, o crescimento de Fop foi decrescente (Figura 1). Esses resultados de crescimento in vitro de Fop estão de acordo com os trabalhos anteriores de Wearing e Burgess (1979) e
Manandhar e Bruehl (1973), que relatam estímulo ao crescimento micelial de Fusarium em meio de cultura com a diminuição do potenciais hídrico, até um valor limitante.

A porcentagem de germinação das sementes é inversamente proporcional à colonização de Fop nas mesmas; portanto, a maior porcentagem de germinação das sementes da testemunha, após inoculação com Fop, parece ser devida ao aumento do crescimento do fungo sobre as sementes que proporcionaram os tratamentos de restrição hídrica. Por meio desses dados, observou-se variação na germinação das sementes ao utilizar diferentes solutos e tempos de exposição das sementes ao fungo, ocorrendo diminuição da germinação à medida que aumentou o tempo de permanência das sementes sobre o fungo (Figura 2).

Nos testes de germinação, as sementes de feijoeiro inoculadas em substrato contendo cloreto de potássio foram colonizadas intensamente por Fop. De acordo com Brownell \& Schneider (1985), íons de potássio são facilmente acumulados pelas células microbianas, estimulando o seu desenvolvimento. Esse fato parece ter sido reproduzido no presente estudo.

A interação entre soluto e potencial foi significativa, havendo redução da germinação de sementes inoculadas apenas no potencial -1.2 MPa utilizando meio modificado com $\mathrm{KCl}$ (Tabela 1). Porém, o uso de potenciais osmóticos diferenciados não foi determinante ao estímulo do crescimento fúngico sobre as sementes.

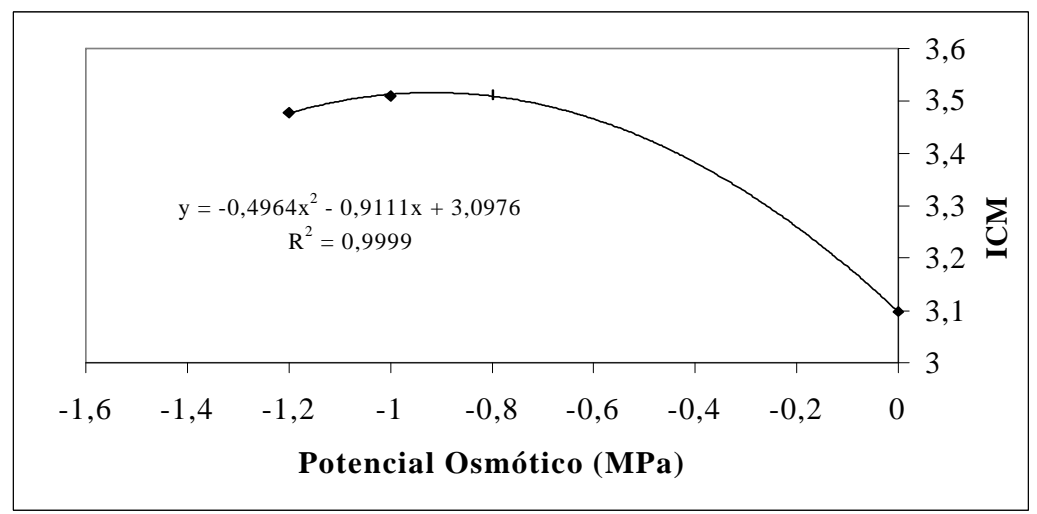

FIGURA 1 - Análise de regressão para índice de crescimento micelial (ICM) de F. oxysporum f.sp. phaseoli em meio BSA variando o potencial osmótico através da concentração dos solutos. UFLA, Lavras-MG, 2000. 


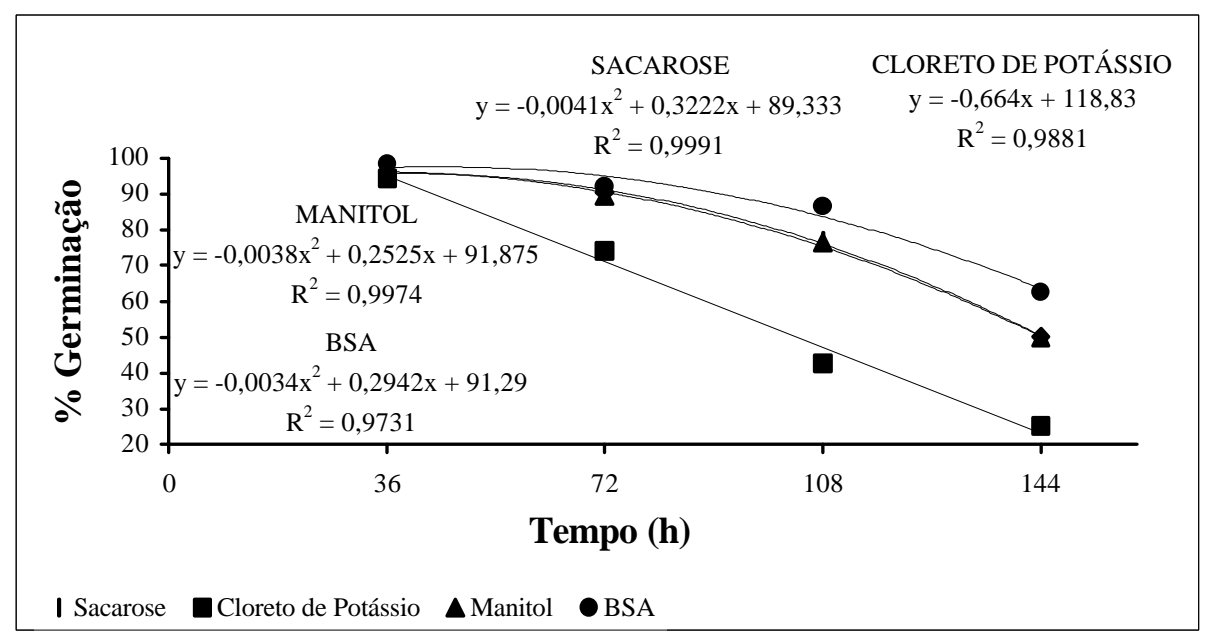

FIGURA 2 - Regressão para \% de germinação das sementes de feijoeiro inoculadas com $F$. oxysporum f. sp. phaseoli em relação aos diferentes tempos de inoculação. UFLA, Lavras-MG, 2000.

TABELA 1 - Média das porcentagens de germinação das sementes inoculadas com $F$. oxysporum f.sp. phaseoli em meio BSA modificado com sacarose, $\mathrm{KCl}$ e manitol. UFLA, Lavras-MG, 2000.

\begin{tabular}{|c|c|c|c|c|c|}
\hline \multirow{2}{*}{ Soluto } & \multicolumn{4}{|c|}{ Potencial osmótico (MPA) } & \multirow{2}{*}{ Média } \\
\hline & $\mathbf{0 , 0}$ & $-0,8$ & $-1,0$ & $-1,2$ & \\
\hline BSA + SACAROSE & - & $79,87 \mathrm{~A}$ & $76,00 \mathrm{~A}$ & $79,12 \mathrm{~A}$ & 78,33 \\
\hline $\mathrm{BSA}+\mathrm{KCL}$ & - & $68,46 \mathrm{~A}$ & $59,75 \mathrm{a}$ & $49,00 \mathrm{~B}$ & 59,11 \\
\hline \multirow[t]{2}{*}{ BSA + MANITOL } & - & $79,75 \mathrm{~A}$ & $79,25 \mathrm{a}$ & $75,12 \mathrm{~A}$ & 78,04 \\
\hline & & & & & $71,83^{*}$ \\
\hline BSA & 85,5 & - & - & - & $85,5^{*}$ \\
\hline
\end{tabular}

Médias seguidas de mesma letra nas colunas são iguais pelo teste Scott-Knott

*Testemunha (BSA) superior ao tratamento pelo contraste entre médias (teste t)

A incidência de Fop foi superior nas sementes de feijoeiro inoculadas que utilizaram meio BSA modificado que em meio BSA. Foram observadas diferenças significativas entre os solutos utilizados, sendo a maior porcentagem de infecção de Fop nas sementes obtida com $\mathrm{KCl}$ (Tabela 2). Não houve diferenças significativas na incidência de Fop nas sementes, entre os diferentes potenciais osmóticos utilizados.

A incidência de Fop nas sementes de feijoeiro após inoculação pelo método de restrição hídrica foi elevada, o que pode ser observado nos resultados de germinação e incidência do fungo. Utilizando a mesma metodologia, mas inoculando Colletotrichun lindemuthianum em sementes de feijoeiro, Carvalho (1999) obteve alta porcentagem do fungo nas sementes inoculadas em meio com restrição hídrica.

Nas avaliações das sementes que permaneceram por maiores períodos de tempo em contato com o fungo, a germinação foi ainda menor, pois aumentando esses períodos, conseqüentemente, aumentou-se a incidência do fungo nas mesmas (Figura 3). 


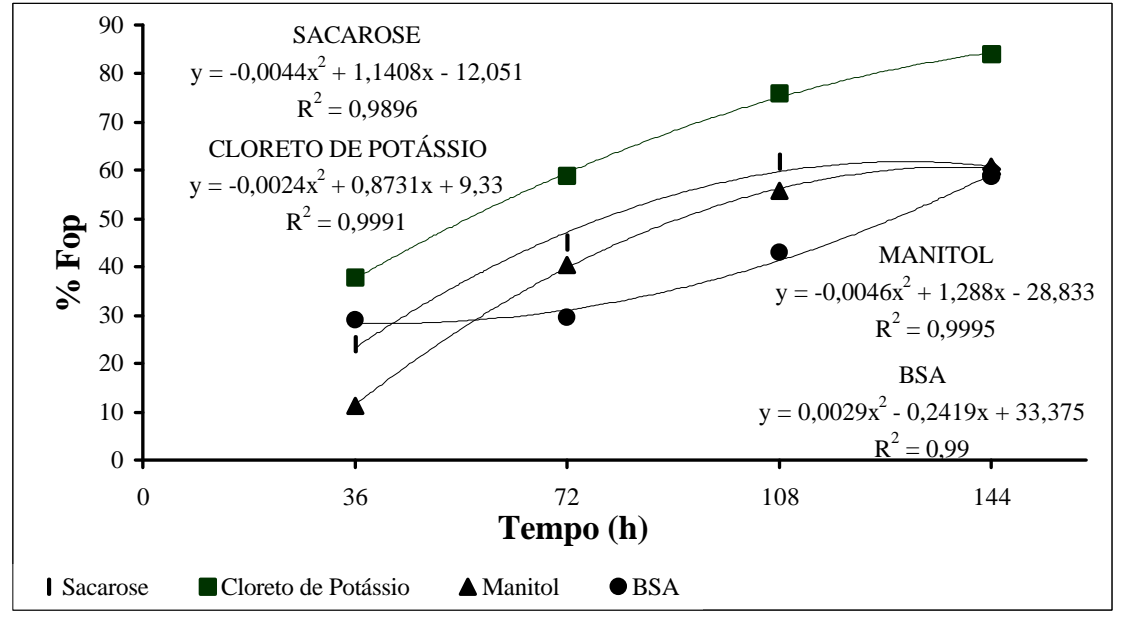

FIGURA 3 - Regressão para porcentagem de $F$. oxysporum f.sp. phaseoli em sementes de feijoeiro nos diferentes solutos e tempos de incubação. UFLA, Lavras-MG, 2000.

TABELA 2 - Incidência $(\%)$ de $F$. oxysporum f.sp. phaseoli e de outros microrganismos em sementes de feijoeiro após inoculação. UFLA, Lavras-MG, 2000 .

\begin{tabular}{lcc}
\hline \multicolumn{1}{c}{ Solutos } & Fop (\%) & Outros (\%) \\
\hline BSA + Sacarose & $49,04 \mathrm{~b}$ & 12,63 \\
BSA + KCl & $64,17 \mathrm{a}$ & 10,88 \\
BSA + Manitol & $42,08 \mathrm{~b}$ & 17,46 \\
\hline Média & $51,76^{*}$ & $13,65^{* *}$ \\
\hline BSA & $38,8^{*}$ & $15,38^{* *}$ \\
\hline
\end{tabular}

Médias seguidas pelas mesmas letras, nas colunas, são estatisticamente iguais pelo teste Scott-Knott (P $\leq \mathbf{0 , 0 5})$

*Tratamento superior à testemunha (BSA) pelo contraste de médias (teste de $\mathrm{t}$ ).

Na Figura 3, valores em torno de $60 \%$ de Fop podem ser observados quando foram utilizados meios $\mathrm{BSA}+\mathrm{KCl}$ em incubação de $72 \mathrm{~h}$ e/ou BSA+sacarose por 108h. Verifica-se então que a incidência de Fop nas sementes é variável de acordo com a combinação soluto e tempo de incubação.

A permanência das sementes sobre o Fop em meio sólido, sem ocorrência de germinação das mesmas, por tempo prolongado $(144 \mathrm{~h})$ foi possível em em razão da adição de solutos ao substrato, promovendo restrição hídrica. Portanto, essa técnica favoreceu a obtenção de sementes de feijoeiro comum com incidência diferenciada de Fop, de acordo com o tempo de incubação.

\section{CONCLUSÕES}

a) A inoculação das sementes de feijoeiro por meio da técnica de restrição hídrica possibilita a obtenção de sementes portadoras de $F$. oxysporum f. sp. phaseoli em níveis diferenciados de infecção.

b) Os solutos sacarose, cloreto de potássio e manitol proporcionaram restrição hídrica ao meio sólido BSA, suficientes para inibir a germinação das sementes durante a colonização por $F$. oxysporum $\mathrm{f}$. sp. phaseoli.

c) O fungo $F$. oxysporum f. sp. phaseoli não teve seu crescimento inibido pelos solutos utilizados durante a colonização das sementes de feijoeiro.

d) A variação nos potenciais osmóticos utilizados não acarretou mudanças significativas na colonização fúngica das sementes pelo $F$. oxysporum f. sp. Phaseoli, podendo, portanto, ser utilizado o maior potencial osmótico, - $0,8 \mathrm{MPa}$.

e) Maiores períodos de incubação das sementes proporcionaram maior porcentagem de sementes colonizadas, havendo, conseqüentemente, diferentes níveis de infestação. 


\section{REFERÊNCIAS BIBLIOGRÁFICAS}

ADEBAYO, A. A.; HARRIS, R. F. Fungal growth responses to osmotic as compared to matric water potential. Soil Science Society of America Proceedings, Madison, v. 85, n. 3, p. 465-469, May/June 1971.

AGARWAL, V. K.; SINCLAIR, J. B. PRINCIPLES OF SEED PATHOLOGY. FLÓRIDA: BOCA RATON, 1987. V. 1, 175 P.

ALAM, S.; JOYCE, D.; WEARING, A. Effects of equilibrium relative humidity on in vitro growth of Botrytis cinerea and Alternaria alternata. Australian Journal of Experimental Agriculture, East Melbourne, v. 36, n. 3, p. 383-388, 1996.

BRASIL. Ministério da Agricultura. Regras para análise de sementes. Brasília: LANARV/SNAD/MA, 1992. $360 \mathrm{p}$

BROWNELL, K. H.; SCHNEIDER, R. W. Roles of matric and osmotic componentes of water potential and their interaction with in the growth for Fusarium oxysporum in synthetic media and soil. Phytopathology, Saint Paul, v. 75, n. 1, p. 53-57, Jan. 1985.

CARVALHO, J. C. B. de. Uso da restrição hídrica na inoculação de Colletotrichum lindemunthianum em sementes de feijão (Phaseolus vulgaris L.). 1999. 98 p. Dissertação (Mestrado em Fitotecnia) - Universidade Federal de Lavras, Lavras, 1999.

CHANDLER, D.; HEALE, J. B.; GILLESPIE, A. T. Effect of osmotic potential on the germination of conidia and colony growth of Verticillium lecanii. Mycological Research, Cambridge, v. 98, n. 4, p. 384-388, 1994.

COOK, R. J.; DUNIWAY, J. M. Water relations in the life-cycles of soilborne plant pathogens. In: PARR, J. F.; GARDNER, W. R.; ELLIOT, L. F. (Eds.). Water potential relations in soil microbiology. Madison: Soil Science Society of America, 1981. p. 119-139.

COUTINHO, W. M. Uso da restrição hídrica no controle da germinação de sementes de arroz (Oryza sativa L.) e feijoeiro (Phaseolus vulgaris L.) em testes de sanidade. 2000. 78 p. Dissertação (Mestrado em Fitopatologia) - Universidade Federal de Lavras, Lavras, 2000 .
KENDRICH, J. B.; SNYDER, W. C. Fusarium yellows of beans. Phytopathology, Saint Paul, v. 32, p. 10101014, 1942.

LEAL, E. C.; BOLKAN, H. A. Ocorrência de Fusarium spp., Rhizoctonia solani e Pythium spp. em sementes de feijão. Fitopatologia Brasileira, Brasília, v. 6, n. 3, p. 580, out. 1981. (Resumo, 111).

MACHADO, A. Q. Uso da restrição hídrica em testes de sanidade de semente de algodoeiro. 2002. 55 p. Dissertação (Mestrado em Fitopatologia) - Universidade Federal de Lavras, Lavras, 2002.

MACHADO, J. da C. Patologia de sementes: fundamentos e aplicações. Lavras: UFLA/FAEPE, 1988. 106 p.

MACHADO, J. da C. Patologia de sementes. Lavras: UFLA, 1999. Apostila.

MANANDHAR, J. B.; BRUEHL, G. W. In vitro interactions of Fusarium and Verticillium wilt fungi with water, $\mathrm{pH}$ and temperature. Phytopathology, Saint Paul, v. 63, p. 413-419, 1973.

MENEZES, J. R.; MOHAN, S. K.; BIANCHINI, A.; SOUZA, G. L. Qualidade sanitária de sementes de feijão (Phaseolus vulgaris L.) no estado do Paraná. Fitopatologia Brasileira, Brasília, v. 6, n. 3, p. 497-507, out. 1981.

MENTEN, J. O. M. Prejuízos causados por patógenos associados às sementes. In: MENTEN, J. O. M. Patógenos em sementes: detecção, danos e controle químico. São Paulo: ESALQ/USP, 1991. p. 115-136.

MICHEL, B. E.; RADCLIFFE, D. A COMPUTER PROGRAM RELATING SOLUTE POTENCIAL TO SOLUTION COMPOSITION FOR FIVE SOLUTES. AGRONOMY JOURNAL, MADISON, V. 87, N. 1, 1995.

NIREMBERG, H. I. A simplified method for identifyng Fusarium spp. occurring on wheat. Canadian Journal of Botany, Ottawa, v. 59, n. 9, p. 1599-1609, Sept. 1981.

NUNES JÚNIOR, J.; MENTEN, J. O. M. Levantamento de fungos associados às sementes de feijão (Phaseolus vulgaris L.) no estado de Santa Catarina. Summa Phytopathologica, Piracicaba, v. 11, n. 1/2, p. 12-13, jan./jun. 1985. 
OLIVEIRA, J. A. Efeito do tratamento fungicida em sementes e no controle de tombamento de plântulas de pepino (Cucumis sativus L.) e pimentão (Capsicum anum L.). 1991. 111 f. Dissertação (Mestrado em Fitossanidade) Escola Superior de Agricultura de Lavras, Lavras, 1991.

PEREIRA, G. V.; YOKOYAMA, L. P. Produção e uso de sementes de feijão no Estado de Goiás. In: REUNIÃO ANUAL DE PESQUISA DE FEIJÃO, 6., 1999, Salvador. Resumos... Salvador: [s.n.], 1999. p. 580-583.

RAVA, A. C.; SARTORATO, A. E.; COSTA, J. G. C. Reação de genótipos de feijoeiro comum ao Fusarium oxysporum f.sp. phaseoli em casa de vegetação. Fitopatologia Brasileira, Brasília, v. 21, n. 2, p. 296-300, 1996.

SANTOS, G. R.; COSTA, H.; PELUZIO, J. M.; MIRANDA, G. V. Transporte, transmissibilidade e patogenicidade da micoflora associada às sementes de feijão (Phaseolus vulgaris L.). Revista Ceres, Viçosa, v. 43, n. 249, p. 621-627, 1996.

WEARING, A. H.; BURGESS, L. W. Water potential and the saprophytic growth of Fusarium roseum 'Graminearum'. Soil Biology and Biochemistry, Oxford, v. 11, n. 6, p. 661-667, 1979. 